\title{
ASPECTOS CRÍTICOS DE LA INVALIDACIÓN ADMINISTRATIVA EN LA LEY 19.880: ANÁLISIS EN LA JURISPRUDENCIA DE LA CONTRALORÍA GENERAL DE LA REPÚBLICA A 8 AÑOS DE SU VIGENCIA*
}

CRITICAL ISSUES OF THE INVALIDATION ADMINISTRATIVE ACT NUMBER 19.880: ANALYSIS OF THE JURISPRUDENCE OF CONTRALORÍA GENERAL DE LA REPÚBLICA IN HIS 8 YEARS OF EXISTENCE

QUESTIONS CRITIQUES DE LA LOI 19.880 SUR L'INVALIDATION ADMINISTRATIF: ANALYSE DE LA JURISPRUDENCE DU CONTRÔLEUR GÉNÉRAL DE LA RÉPUBLIQUE EN SES 8 ANS DE EXISTENCE

José Luis Lara Arroyo**

Gonzalo Guerrero Valle***

\begin{abstract}
RESUMEN
El presente artículo analiza aspectos de la invalidación administrativa que han suscitado discusión. En efecto, a 8 años de la entrada en vigencia de la Ley 19.880 , la jurisprudencia de la Contraloría General de la República se ha manifestado a través de numerosos cuestionamientos respecto de aquella institución, los cuales dicen relación con diversos ámbitos de su aplicación, como la obligatoriedad de la audiencia previa, los casos en que la Contraloría General de la República dispone la necesidad u ordena, derechamente, invalidar un acto administrativo. Además, analiza aspectos como la invalidación de los actos administrativos que se producen dentro del contexto de procedimientos reglados, el plazo para invalidar, si cabe la preclusión en la invalidación, y la relación existente entre la invalidación y la nulidad de derecho público.
\end{abstract}

\footnotetext{
* El artículo fue recepcionado el 17 de julio de 2011, y aprobado para su publicación el 24 de octubre de 2011.

** Abogado. Licenciado en Derecho por la Pontificia Universidad Católica de Chile. Profesor de Derecho Administrativo en la Facultad de Derecho de la Pontificia Universidad Católica de Chile Actualmente cursa el Doctorado en Derecho en la Pontificia Universidad Católica de Chile.

*** Abogado. Licenciado en Derecho por la Pontificia Universidad Católica de Chile. Actualmente cursa el Magíster en Derecho Constitucional en la Pontificia Universidad Católica de Chile. Profesor Instructor Asociado en la cátedra de Historia de Derecho en la Facultad de Derecho de la Pontificia Universidad Católica de Chile.
} 


\begin{abstract}
This article examines aspects of administrative invalidation that have generated discussion. Indeed, 8 years after the entry into force of Law $\mathrm{N}^{\circ} 19.880$, the jurisprudence of the General Comptroller of the Republic has shown through numerous questions about that institution, which are related to various areas of application such as mandatory prior hearing of the cases in which the General Comptroller of the Republic has the need or order, right to invalidate an administrative act. Also, it explores issues such as the invalidation of administrative acts that occur within the context of regulated procedures, the deadline to invalidate, if possible estoppel in the invalidation, and the relationship between the invalidation and nullity of public law.
\end{abstract}

\title{
RÉSUMÉ
}

Cet article traite de la discussion générée sur divers aspects de 1' invalidation administratif. En effet, 8 ans après l'entrée en vigueur de la loi ${ }^{\circ} 19.880$, la jurisprudence du Contrôleur général de la République a manifesté nombreuses questions sur cette institution, qui sont liés à différents domaines d'application tels que l'audience préliminaire obligatoire et le cas où le contrôleur général de la République a le besoin d'invalider un acte administratif. Il aborde également des questions telles que l'invalidation des actes administratifs qui se produisent dans le contexte des procédures réglementées, le term d'invalider, la préclusion de l'invalidation, et la relation entre l'invalidation et nullité du droit public.

Palabras Claves:

Acto administrativo - Invalidación - Jurisprudencia

KeY Words:

Administrative act - Invalidation - Jurisprudence

Mots Clé:

Actes adminitratives- Invalidation- Jurisprudence 


\section{INTRODUCCIÓN}

El Estado y sus organismos tienen por finalidad la consecución del bien común respetando los derechos de las personas, con plena sujeción a la Constitución y a las normas dictadas conforme a ella ${ }^{1}$. El cumplimiento de dichas finalidades importa el ejercicio de precisas potestades públicas con el objeto de satisfacer necesidades públicas concretas.

Ahora bien, dicho actuar administrativo puede manifestarse, ya sea a través de un actuar jurídico unilateral, o bien contando con el concurso de la voluntad de otro órgano (convenio) o de un particular (contrato administrativo).

El objeto de este trabajo es preocuparnos de la actividad jurídica unilateral del Estado, esto es, de las decisiones formales de la Administración (acto administrativo), que son producto de una concatenación o secuencia de actos trámites destinados a la dictación o constitución ${ }^{2}$ de un acto terminal denominado acto administrativo, que en cuanto ha sido dictado conforme a Derecho (Principio de Juridicidad) produce todos sus efectos (imperatividad, ejecutoriedad y presunción de legalidad) ${ }^{3}$, y en cuanto ha sido dictado con infracción al ordenamiento jurídico genera su ineficacia, susceptible de remediarse en el orden judicial (nulidad y responsabilidad) o bien en el orden administrativo (invalidación).

Pues bien, en tal sentido, la invalidación se erige como una forma de extinción del acto administrativo (junto con la caducidad y la revocación) ${ }^{4}$. Dicho mecanismo no ha estado exento de críticas por parte de la doctrina para quienes carece de todo sustento jurídico ${ }^{5}$, desde el momento en que sería la propia administración quien por sí y ante sí retira un acto por estimarlo contrario a Derecho, consagrándose una verdadera autotutela declarativa. Sin perjuicio de ello, y compartiendo los fundamentos y cuestionamientos respecto de la institución, lo cierto es que con la Ley 19.880 se vino a consagrar la potestad invalidatoria

1 Conforme a los términos previstos en el artículo 1 de la Constitución Política de la República.

2 Bocksang Hola, Gabriel. El Procedimiento Administrativo Chileno. Estudio Analítico y Sistemático de Coherencia. Santiago: Editorial LexisNexis, 2006, p. 195.

3 Conforme a los términos previstos en el artículo 3 de la Ley $N^{\circ} 19.880$, Ley de Bases de los Procedimientos Administrativos que rigen los actos de los Órganos de la Administración del Estado, 22 de mayo de 2003.

$4 \mathrm{Al}$ respecto, Poblete Vinaixa, Julia. Actos y Contratos Administrativos. $5^{\text {a }}$ Edición. Santiago: Editorial LegalPublishing, 2010, pp. 61 y ss; Boloña Kelly, Germán. El Acto Administrativo. 2a Edición. Santiago: Ediciones LegalPublishing, 2007, pp. 265 y ss.

5 Soto KLoss, Eduardo. "La Ley 19.880, sobre Procedimientos administrativos, ¿"Aleluya” о "Miserere”?". En: Soto KLoss, Eduardo (Edit.). Ley $N^{\circ} 19.880$, sobre Procedimientos Administrativos. Santiago: Ediciones Universidad Santo Tomás, 2003, pp. 95 y ss. 
de la Administración del Estado ${ }^{6-7}$.

De esta forma, la invalidación administrativa es un mecanismo de impugnación de los actos de la Administración del Estado que, incluso a partir de la entrada en vigor de la Ley 19.880 que la consagra, no ha estado exenta de discusiones en lo que a su operatividad se refiere. En efecto, a más de 8 años de la entrada en vigencia de la Ley 19.880, que consagra aquel instituto en forma general en nuestro ordenamiento jurídico, se mantienen numerosos cuestionamientos a aquella institución, los cuales dicen relación con diversos ámbitos de su aplicación ${ }^{8}$.

Así, han existido discusiones que ya han sido superadas; por ejemplo, cuál es el órgano competente para invalidar, pero otras, como es el caso de la factibilidad de invalidar reglamentos, que constituyen materias cuya discusión está recién comenzado a propósito del Dictamen $\mathrm{N}^{\circ} 39.979$, de 2010, que da cabida a la invalidación de reglamentos.

Pero la disputa no queda ahí, sino que se extiende a otras áreas de la invalidación. En efecto, en esta investigación se han querido tratar los aspectos críticos de la invalidación, entre los cuales se analizarán: la obligatoriedad de la audiencia previa en los casos en que la Contraloría General de la República dispone la necesidad u ordena, derechamente, invalidar un acto administrativo; la invalidación de los actos administrativos que se producen dentro del contexto de procedimientos reglados; el plazo para invalidar; si cabe la preclusión en la invalidación; y la relación existente entre la invalidación y la nulidad de derecho público.

\footnotetext{
6 En tal sentido, la jurisprudencia de Contraloría General ha sido clara en orden a sostener, mediante dictamen $\mathrm{N}^{\circ}$ 33.451 de 2006 que "Cabe precisar que el debate sobre la naturaleza y la procedencia misma de la institución jurídica de la invalidación fue zanjado definitivamente con la dictación de la Ley $N^{\circ} 19.880$, publicada en el Diario Oficial del 29 de mayo de 2003, la cual establece las bases de los procedimientos administrativos que rigen los actos de la Administración del Estado, cuyo articulo 53 reconoce que "la autoridad administrativa podrá, de oficio o a petición de parte, invalidar los actos contrarios a derecho, previa audiencia del interesado, siempre que lo haga dentro de los dos años contados desde la notificación o publicación del acto", decisión que, obviamente, será siempre impugnable ante los Tribunales de Justicia. Lo anterior es tan evidente que ninguno de los numerosos fallos citados por el actor es posterior a la fecha de vigencia del referido cuerpo legal. Por el contrario, la Corte de Apelaciones de Valdivia, en sentencia de 30 de agosto de 2005, rol No 3830-05, confirmada por la Excma. Corte Suprema, declaró que "el Alcalde recurrido debia dar cumplimiento a lo señalado en el Dictamen $N^{\circ} 162$, de 10 de enero de 2005, y dejar sin efecto los decretos de nombramientos fundados en un concurso que se estimó viciado por el órgano Contralor, de manera que los decretos impugnados no fueron dictados en forma arbitraria e ilegal, sino en cumplimiento de una obligación que vincula a la Municipalidad con la Contraloría General de la República".

7 Vid Bermúdez Soto, Jorge. Derecho Administrativo General. Santiago: Ediciones LegalPublishing, 2010 , pp. 100 y ss.

8 Vid Soto KLoss (2003).
} 


\section{Cuestiones previas y pacíficas sobre la INVAlidación Administrativa}

\section{A. Caracterización de la Invalidación}

Si bien la Contraloría General de la República no da un concepto de lo que entiende por invalidación administrativa luego de la entrada en vigencia de la Ley 19.880, es preciso señalar que esta se puede entender como un retiro, ya que invalidar un acto es retirarlo del mundo jurídico en que existe, en atención a que adolece de un vicio por infracción a Derecho9. Lo anterior se efectúa mediante una manifestación de voluntad de contrario imperio al acto administrativo inicial ${ }^{10}$.

De ese modo, se puede apreciar que en la invalidación hay dos actos: uno, el acto original sujeto a la potestad invalidatoria; y otro, el acto invalidatorio.

Como se señaló, la invalidación constituye un retiro de un acto administrativo, ya que es manifestación de voluntad de contrario imperio al acto impugnado, puesto que la Administración es la que dicta un acto administrativo inicial, debiendo posteriormente dictar otro que deja sin efecto el acto impugnado. Al ser dicho acto, uno de contrario imperio al acto inicial, se pone término anticipadamente al acto administrativo, porque la Administración identifica un vicio de derecho, lo interrumpe y deja sin efecto. Más aún, la autoridad administrativa, identificado el vicio, debe invalidar ${ }^{11}$.

Ahora bien, para que proceda la invalidación el acto invalidado debe adolecer de un vicio de derecho, por cuanto la invalidación es un mecanismo de control de la Administración sobre sus propios actos ${ }^{12}$. En tal sentido, el acto invalidado necesariamente, como ya se ha dicho, debe adolecer de un vicio, cuya gravedad lo hace susceptible de tal sanción. Tal vicio es una irregularidad que puede consistir en cualquiera de los vicios del acto administrativo con la prevención dispuesta a propósito de la esencialidad de este, respecto de la cual nos pronunciaremos más adelante en este trabajo.

Por último, dentro de los presupuestos necesarios para invalidar, es necesario que el órgano de la Administración que invalida posea la habilitación para invalidar, no siendo tal una potestad implícita, puesto que el ordenamiento

9 Para Celis, la Invalidación consiste en "dejar sin efecto el acto administrativo por la misma autoridad que dispuso la medida irregular, atendido que adolece de un vicio de ilegalidad o inconstitucionalidad. Celis Danzinger, Gabriel. Curso de Derecho Administrativo. Tomo I. Santiago: Ediciones PuntoLex, 2010, p. 426.

10 Cf. Olguín JuÁrez, Hernán. Extinción de los actos administrativos. Revocación, invalidación y decaimiento. Santiago: Editorial Jurídica de Chile, 1961, pp. 229 y ss.

11 Dictamen $\mathrm{N}^{\circ}$ 28.477, de 2006.

12 Cf. Aylwin Azócar, Patricio. Derecho Administrativo. Santiago: Editorial Universidad Nacional Andrés Bello, 2006, pp. 209 y ss. 
jurídico debe conferirlo expresamente conforme a los términos de los artículos 6 y 7 de nuestra Carta Fundamental.

Así, al tenor del artículo 53 de la Ley 19.880, la cual dispone que: "La autoridad administrativa podrá, de oficio o a petición de parte, invalidar los actos contrarios a derecho, previa audiencia del interesado, siempre que lo haga dentro de los dos años contados desde la notificación o publicación del acto. La invalidación de un acto administrativo podrá ser total o parcial. La invalidación parcial no afectará las disposiciones que sean independientes de la parte invalidada.

El acto invalidatorio será siempre impugnable ante los Tribunales de Justicia, en procedimiento breve y sumario"'13.

El órgano competente para invalidar será siempre la autoridad administrativa, no señalando cuál es esa autoridad.

Respecto al punto recién comentado, cabe señalar que, quizás, el motivo por el cual no se identificó claramente al órgano competente para invalidar se debe al hecho de que la propia Ley 19.880, en su artículo primero, dispone su carácter supletorio de las diversas normas que establecen procedimientos administrativos $^{14}$.

\section{B. ÓRgANO COMPETENTE PARA INVALIDAR}

Si bien, como ya se ha dicho, el artículo 53 de la Ley $N^{\circ} 19.880$ señala que la autoridad administrativa podrá (y en realidad deberá) invalidar, la citada disposición no específica qué autoridad será la competente para realizar y llevar a efecto la invalidación ${ }^{15}$.

No obstante, y dado el vacío que en relación con este aspecto ha dejado la norma, fue la Contraloría General de la República la que, mediante sus interpretaciones comenzó a llenar aquellas fisuras de la ley citada, sin perjuicio de los pronunciamientos anteriores a la vigencia de la norma en cuestión ${ }^{16}$. En

\footnotetext{
13 Ley $\mathrm{N}^{\circ}$ 19.880, Establece bases de los procedimientos administrativos que rigen los actos de los órganos de la administración del estado. Diario Oficial, 29 de mayo de 2003.

$14 \mathrm{El}$ inciso primero del artículo $1^{\circ}$ de la Ley $\mathrm{N}^{\circ} 19.880$, de 2003 , dispone que "La presente ley establece y regula las bases del procedimiento administrativo de los actos de la Administración del Estado. En caso de que la ley establezca procedimientos administrativos especiales, la presente ley se aplicará con carácter de supletoria".

15 En la especie, la competencia supone un "conjunto de poderes jurídicos con que el Derecho dota, provee, o habilita, a un órgano para que actuando éste en la vida de relación de sujeto jurídico impute unitariamente los efectos de su actuación a este sujeto, y pueda así cumplir los fines para los cuales ha sido precisamente creado por el legislador”. En Soto KLoss, Eduardo. Derecho Administrativo. Temas Fundamentales. Santiago: Editorial LegalPublishing, 2009, p. 125.

16 En efecto, la Contraloría General de la República, mediante su Dictamen N²1.719, de 1972, señaló que "la autoridad debe ajustar sus decisiones a normas que regulan las materias en que recaen, correspondiéndole dejar sin efecto medidas ilegales o basadas en presupuestos erróneos, aun ya tramitados, para restablecer el orden jurídico alterado. No obstante, la invalidación de actos irregulares puede estar limitada por la necesidad de mantener las situaciones juridicas producidas como consecuencia de actuaciones ilegitimas, pues no pueden desconocerse los efectos derivados de actos defectuosos, particularmente si alcanzan a terceros y se han creado al amparo de presunta legitimidad
} 
efecto, después de la entrada en vigencia de la norma aludida, el ente de control ha reiterado en numerosos pronunciamientos que el órgano competente para invalidar es la autoridad que dictó el acto impugnado, esto es, que dispuso la medida supuestamente irregular.

En efecto, a través de su Dictamen N $\mathrm{N}^{\circ}$ 56.840, de 2010, la Contraloría ha expresado que "cabe señalar que este Ente Contralor ha manifestado, en sus dictámenes Nos 53.146, de 2005 y 27.879, de 2008, entre otros, que tal determinación le corresponde a la misma autoridad que dispuso el acto que se impugna, a través de la emisión de un nuevo decreto o resolución que ordene dejar sin efecto el primitivamente dictado, aun cuando éste haya cumplido con el trámite de toma de razón ante este Órgano Fiscalizador, y siempre que, por cierto, tal decisión sea procedente y los vicios se encuentren fehacientemente acreditados, por lo que aquélla debe formularse ante la superioridad de la cual emanó el acto administrativo que pretende impugnar, y no ante este Ente de Control"'17.

Así, se puede concluir que solo la autoridad que dictó el acto impugnado se encuentra habilitada para retirarlo del ordenamiento jurídico mediante la dictación de un acto posterior que lo deje sin efecto o derogue, puesto que ello implica una potestad conferida al ente administrativo para llevar adelante el procedimiento del que se trata, teniendo a la vista el fin último de este, el cual es la satisfacción de una necesidad pública.

Sin perjuicio de lo anterior, las interpretaciones de la Contraloría no permiten vislumbrar claramente si todo tipo de acto es retirable mediante la invalidación. Este tema, será materia de análisis posterior en este trabajo.

\section{LÍMITES DE DE INVALIDACIÓN}

Desde antiguo, existen diversos pronunciamientos de la Contraloría General de la República que han identificado límites a la potestad invalidatoria de la Administración. En efecto, VARGAs Zincke enumera tres límites a la antedicha potestad con anterioridad a la entrada en vigencia de la Ley 19.880, los cuales son $^{18}$ : la necesidad de mantener situaciones jurídicas que se producen como consecuencia de actuaciones ilegítimas de la autoridad ${ }^{19}$; afectación de los de-

derivada de que el acto irregular fue tomado de razón".

17 En el mismo sentido, pueden consultarse los dictámenes $N^{\circ} 22.983$ de 2010; 65.786, de 2009; 36.701, de 2008; 19.551, de 2008; 33.200, de 2007; 23.120, de 2007; y, 17.329, de 2007, entre otros, todos de la Contraloría General de la República. 18 Vargas Zincke, Osvaldo. "Algunos aspectos de la invalidación en la jurisprudencia de la Contraloría General de la República”. En: Verdugo Marinkovic, Mario (Dir.). Gaceta Jurídica, N 178. Santiago: Editorial Jurídica ConoSur Limitada, 1995, pp. 38-41.

19 Sobre el particular, el Dictamen $\mathrm{N}^{\circ}$ 24.049, de 1969, señaló que "no cabe invalidar ascenso ya tramitado, porque la medida significaría suprimir efectos producidos en el tiempo intermedio y que han alcanzado a terceros". La jurisprudencia en cuestión ya había sido establecida con anterioridad mediante el Dictamen $\mathrm{N}^{\circ} 24.192$, de 1960. 
rechos adquiridos de buena $\mathrm{fe}^{20}$; y la irretroactividad de la invalidación ${ }^{21}$.

Sin perjuicio de lo dicho, con posterioridad a la entrada en vigor de la Ley de Procedimiento Administrativo, la jurisprudencia contralora ha señalado como límites a la invalidación los siguientes:

\section{i. Derechos adquiridos}

La jurisprudencia de la Contraloría ha reconocido a los derechos adquiridos como uno de los límites al ejercicio de la potestad invalidatoria ${ }^{22}$. En efecto, como ya se señaló, aquel es un límite que se reconoce desde antes de la entrada en vigencia de la Ley 19.880, y que luego de su entrada en vigor se ha visto fortalecido. El problema surge, toda vez que esta ley no dispuso expresamente como límite a la invalidación el respeto a los derechos adquiridos de buena fe, como sí lo hace tratándose de otra forma de extinguir el acto administrativo, como en la especie acontece con la revocación.

De esta manera, el advenimiento de la Ley 19.880 trajo consigo el riesgo de que se entendiera -bajo una parcial interpretación literalista- que los derechos adquiridos de buena fe no constituyen un límite al ejercicio de la aludida potestad invalidatoria. Sin embargo, la jurisprudencia de la Contraloría, generosa en el resguardo de los derechos de las personas, hace aplicable el límite expreso previsto en la revocación respecto de la invalidación ${ }^{23}$.

Sobre el particular, jurisprudencia de reciente data ha señalado que "tal como lo indica la jurisprudencia de la Contraloría General, comprendida en los dictámenes $N^{\circ}$ s. 25.580, de 2000 y 12.272, de 2002, no resulta posible aplicar la sanción de nulidad cuando ella produce efectos más perniciosos que los que se intentan evitar con esa medida, puesto que, de lo contrario,

\footnotetext{
20 Sobre el particular, el Dictamen $N^{\circ}$ 10.667, de 1994, ha dispuesto que "la invalidación de un acto administrativo irregular está limitada por la necesidad de mantener la estabilidad de las situaciones jurídicas creadas a su amparo, porque no pueden desconocerse los efectos de aquellos, particularmente, cuando dichas consecuencias afectan los derechos de terceros y se ban originado bajo la presunción de legalidad, derivada de la toma de razón del acto defectuoso".

21 Sobre el particular, el Dictamen $\mathrm{N}^{\circ} 28.514$, de 1992, señala que "esta invalidación no afecta los actos jurídicos celebrados por terceros conforme la normativa que abora se deja sin efecto, ni a los derechos que en tales actos se bubieren originado, porque ello excede la competencia de la autoridad administrativa".

22 Cabe señalar que "se ha adquirido un derecho cuando ha ingresado al patrimonio de un sujeto, e ingresa a él de modo diverso según se trate de derechos reales o personales, pues mientras los primeros requieren de un modo de adquirir, los segundos requieren de una fuente jurídica generadora de la obligación y derecho recíproco". En Sото KLoss, Eduardo. Derecho Administrativo. Bases Fundamentales. Santiago: Editorial Jurídica de Chile, 1996, p. 225.

23 Véanse los dictámenes $N^{\circ} 7.348$ de 2008; 16.238, de 2007; y 7.941, de 2006, todos de la Contraloría General de la República.
} 
se atentaría contra principios elementales de seguridad en las relaciones jurídicas, advirtiéndose la conveniencia de proteger a las personas que han actuado de buena fe y de mantener la estabilidad de los hechos jurídicos que revistan caracteres de consolidados, todo lo cual acontece en la especie con las jerarquías otorgadas en el lapso en análisis en base al reglamento de que se trata.

\section{(..)}

Por otro lado, y en lo referente a los procesos de jerarquización sobre los que aún se conserva la facultad de invalidación, cabe señalar que la jurisprudencia administrativa más reciente, contenida, entre otros, en los dictámenes $N^{\circ} s .32 .357$, de 2006, 8.630 y 16.238, de 2007 y 2.965 y 7.348, de 2008, todos de esta Entidad de Control, ha declarado que el ejercicio de la aludida potestad debe ser armonizado con los principios generales informadores del ordenamiento jurídico, como son la buena fe y la seguridad y certeza jurídica, de manera tal que dicha facultad-deber se encuentra limitada, entre otras circunstancias, por la existencia de situaciones jurídicas consolidadas que se han generado sobre la base de la confianza en el actuar de la Administración"

Asimismo, resulta útil recordar lo dispuesto por la Contraloría un año antes de la promulgación de la Ley 19.880: "A su vez, la jurisprudencia administrativa emanada de esta Entidad de Control ha manifestado reiteradamente que debe tenerse presente que la invalidación tiene como límite aquellas situaciones jurídicas consolidadas sobre la base de la confianza de los particulares en la Administración, puesto que la seguridad jurídica de tal relación amerita su amparo. De otro modo, podría presentarse el caos y daños irreparables e injustos, al margen de que por haber producido sus efectos, la nulidad del acto írrito afectaría derechos de terceros, quienes legítimamente los han incorporado a sus patrimonios. Tal criterio se ha manifestado, entre otros, en los dictámenes $N^{o}$ s. 21393, de 1974; 5019 y 17799, de 1990; 24087, de 1991; 15194, de 1995; 44492, de 2000; y 7742, de 2000"25.

Por último, resta señalar que el mencionado límite ha sido reconocido desde antaño. En efecto, un pronunciamiento de 
1995 da cuenta de que "la Administración debe invalidar, esto es, dejar sin efecto retroactivamente, sus actos que adolecen de error de hecho o ilegalidad, en la medida que no hayan generado consecuencias patrimoniales en favor de terceros $y$ que se acredite fehacientemente la existencia de las circunstancias que configuran aquellas causales, supuesto este último que se cumple en el caso en estudio"'26.

\section{ii. Buena fe}

La buena fe es uno de los principios generales inspiradores del derecho que se extiende a todo el ordenamiento jurídico y que supone la convicción de que los destinatarios de un acto jurídico o de una norma se encuentran en una situación regular ${ }^{27}$.

Por su parte, la Contraloría General de la República ha entendido que la buena fe es un límite a la potestad invalidatoria. En efecto, el ente de control ha señalado que "no resulta posible aplicar la sanción de nulidad cuando ella produce efectos más perniciosos que los que se intentan evitar con esa medida, puesto que, de lo contrario, se atentaría contra principios elementales de seguridad en las relaciones jurídicas, advirtiéndose la conveniencia de proteger a las personas que han actuado de buena fe y de mantener la estabilidad de los hechos jurídicos que revistan caracteres de consolidados, todo lo cual acontece en la especie con las jerarquías otorgadas en el lapso en análisis en base al reglamento de que se trata" ${ }^{28}$.

El mencionado límite es uno de aquellos reconocidos con anterioridad a la entrada en vigor de la Ley 19.880. Lo dicho se encuentra expresamente reconocido en el dictamen $\mathrm{N}^{\circ} 2.572$, de 1999, el cual señala que "debe entenderse restringido el ejercicio de la potestad invalidatoria de la Administración cuando el acto administrativo ilegal atenta contra los principios de la seguridad jurídica o la certeza derivada de ella y la buena fe de los terceros involucrados, esto es, la creencia de encontrarse en una situación regular y legítima".

\footnotetext{
26 Dictamen $\mathrm{N}^{\circ} 23.851$, de 1995.

27 El profesor Carlos Dúcl conceptualiza a la buena fe como "una actitud mental, actitud que consiste en ignorar que se perjudica un interés ajeno o no tener conciencia de obrar contra derecho, de tener un comportamiento contrario a él". En Ducci Claro, Carlos. Derecho Civil. Parte General. Santiago: Editorial Jurídica de Chile, 2005, p. 29.

28 Dictamen $\mathrm{N}^{\circ} 8.058$, de 2009.
} 


\section{iii. Seguridad jurídica}

Al igual que los principios recién descritos, la seguridad jurídica importa un principio informador del ordenamiento jurídico de vital importancia. "La noción de seguridad jurídica hunde sus raíces en el Derecho romano, específicamente en los conceptos de certitudo y seguritas desarrollados por los jurisconsultos de la época. El primero exigía que el sujeto del derecho sepa con anticipación cuál es el comportamiento jurídico que se espera de él y de sus semejantes. De este modo la ley no debía ser ni vaga ni dejar margen a la discrecionalidad del encargado de aplicarla ni poner en duda los derechos establecidos"29.

Como consecuencia de la vigencia de la Ley 19.880, el mencionado principio ha recibido un reforzamiento como principio de la potestad invalidatoria de la Administración al señalar la jurisprudencia de la Contraloría General de la República que "no resulta posible aplicar la sanción de nulidad cuando ella produce efectos más perniciosos que los que se intentan evitar con esa medida, puesto que, de lo contrario, se atentaría contra principios elementales de seguridad en las relaciones jurídicas, advirtiéndose la conveniencia de proteger a las personas que han actuado de buena fe y de mantener la estabilidad de los hechos jurídicos que revistan caracteres de consolidados, todo lo cual acontece en la especie con las jerarquías otorgadas en el lapso en análisis en base al reglamento de que se trata" 30 .

Sin perjuicio de lo dicho, el mencionado ente de control había señalado con anterioridad a la promulgación de la citada Ley de Procedimiento Administrativo que "si bien la Administración, en ejercicio de su potestad invalidatoria, se encuentra habilitada para enmendar sus actuaciones originadas en vicios de legalidad, ello encuentra su límite en superiores principios de orden público, como son la paz social, la certeza jurídica, el principio de racionalidad, la equidad, etc., así como los derechos garantizados expresamente por la Constitución Política del Estado, situación que corresponde ponderar y evaluar en cada caso" ${ }^{\prime 31}$.

29 CoRtés Sepúlneda, Aristóteles. “¿Texto, contexto o pretexto? Por una teoría normativa de la seguridad jurídica”. Actas de las XXXIV Jornadas de Derecho Público. Facultad de Derecho de la Pontificia Universidad Católica de Chile, Santiago: Lexis Nexis, 2005, pp. 57-58.

30 Dictamen $\mathrm{N}^{\circ} 8.058$, de 2009.

31 Dictamen $\mathrm{N}^{\circ} 12.500$, de 2002. 
Otro ejemplo del antedicho reconocimiento se encuentra en el pronunciamiento que dispone que "no procede la invalidación de actos administrativos irregulares cuando éstos han producido todos sus efectos respecto de terceros, como ocurre con los ascensos, lo cual, en todo caso, no impide que a futuro se implementen las medidas pertinentes tendientes a subsanar cabalmente la situación de la interesada ${ }^{\prime 32}$.

\section{iv. Confianza legítima en los actos}

El principio de la confianza legítima en los actos de la Administración del Estado "supone el amparo que debe dar el juez al ciudadano frente a la Administración Pública, la que ha venido actuando de una determinada manera, en cuanto esta lo seguirá haciendo de esa misma manera en lo sucesivo y bajo circunstancias (políticas, sociales, económicas) similares" ${ }^{\prime 33}$.

El mencionado principio ha recibido amplio reconocimiento por parte de la Contraloría General de la República como un límite a la potestad invalidatoria. En efecto, ese ente de control ha sostenido que "no todo vicio conduce necesariamente a la invalidación de los actos administrativos, de modo que para definir la forma de proceder al respecto, el municipio debe considerar el tiempo transcurrido desde la ocurrencia de la irregularidad, la buena fe del contribuyente -si actuó con el convencimiento que el acto administrativo se ajustaba a derecho-, el principio de seguridad jurídica y la confianza en los actos de la Administración, la que no puede aprovecharse de su propia negligencia" ${ }^{\prime 3}$.

\section{v. Prescripción adquisitiva}

La Contraloría General ha dispuesto que la prescripción adquisitiva limita la potestad para invalidar. En tal sentido ha señalado que "la jurisprudencia administrativa contenida en los dictámenes $N^{\circ}$ s. 23.942, de 2003, 42.506, de 2004, y 4.350, de 2008, de este Organismo Fiscalizador, ha concluido que la existencia de un vicio que pudiere producir la invalidación de un acto de concesión de un beneficio, no impide que éste se

32 Dictamen $\mathrm{N}^{\circ}$ 11.177, de 1988.

33 Bermúdez Soto, Jorge. "El principio de confianza legítima en la actuación de la Administración como límite a la potestad invalidatoria". Revista de Derecho (Valdivia), Volumen XVIII, No 2. Facultad de Derecho de la Universidad Austral, 2005, Valdivia, p. 85.

34 Dictamen $\mathrm{N}^{\circ} 48.554$, de 2004. 
incorpore irrevocablemente al patrimonio de su titular por el vencimiento de los plazos de prescripción adquisitiva, dado que habiendo transcurrido, desde la concesión de aquél, un plazo mayor a los cinco años indicados por las normas generales de prescripción contenidas en el Código Civil, se han extinguido todas las acciones que se pudieron ejercer en su momento para cuestionar la validez de dicho acto" 35 .

Asimismo, el ente de control ha manifestado que "no procede dejar sin efecto el decreto $N^{\circ} 194$ de 1999 que concedió pensión no contributiva al señor E.R., toda vez que aun cuando se haya comprobado posteriormente que la citada persona no reunía el tiempo mínimo para dicho beneficio, ha transcurrido el plazo de 2 años señalado por el artículo 53 de la Ley $N^{\circ}$ 19.880, para la invalidación de dicho acto administrativo contrario a derecho, por lo tanto, esa franquicia previsional la incorporó definitiva e irrevocablemente a su patrimonio sin que corresponda que la administración deje sin efecto el acto que la reconoció, tal como lo ha manifestado este Organismo de Control en su dictamen $N^{\circ} 26.005$ del 2006"36.

\section{vi. Proporcionalidad}

Asimismo, la Contraloría General ha identificado que el principio de proporcionalidad constituye una limitación a la invalidación.

La proporcionalidad "instituye una relación de medio a fin, como asimismo de utilidad de un acto, confrontando el fin de una intervención con los efectos de esta posibilitando un control de exceso, protegiendo a las personas respecto de los abusos o arbitrariedad del poder estatal"'37.

En la especie, el organismo de control señaló que "si esta Entidad de Control estima que la sustanciación del sumario adolece de vicios de legalidad que hacen procedente su invalidación, o bien, que la sanción aplicada carece de proporcionalidad respecto de la falta en que incurrió el sumariado, ordenará retrotraer el proceso sumarial, entendiéndose que la medida nunca ha producido sus efectos, debiendo el funcionario reasumir sus funciones ${ }^{\prime 38}$.

35 Dictamen $\mathrm{N}^{\circ} 17.563$, de 2008.

36 Dictamen $\mathrm{N}^{\circ} 38.612$, de 2006.

37 Nogueira AlcalÁ, Humberto. "El principio de proporcionalidad y su aplicación en Sudamérica por la jurisdicción constitucional, con especial mención al Tribunal Constitucional chileno". En: CARBONELL, Miguel (Edit.). El principio proporcional en la interpretación jurídica. Santiago: Librotecnia, 2010, p. 355.

38 Dictamen $\mathrm{N}^{\circ} 4.933$, de 2005. 


\section{Aspectos CRÍticos de la InVALIDACión}

Como se señaló, la invalidación posee aspectos que ya han sido zanjados por la jurisprudencia, sin que exista mayor discusión al respecto, pero existen otros que están abiertos a la discusión y que es preciso exponer en este trabajo.

\section{A. LA “AUDIENCIA PREVIA" y SU OBLIGATORIEDAD}

El artículo 53 de la Ley 19.880 consagra la audiencia previa como un trámite necesario para invalidar un acto administrativo. De esta manera, el legislador materializa principios constitucionales del justo y racional procedimiento (art. $19 \mathrm{~N}^{\circ} 3$ de la Constitución) en un trámite que, en definitiva, importa conferir una oportunidad para que los interesados en el procedimiento invalidatorio puedan exponer argumentos y antecedentes sobre la procedencia de este. Sin embargo, el legislador no efectuó un tratamiento más pormenorizado de esta etapa procedimental, por lo que debiéramos remitirnos a las normas generales en lo que refiere a la forma, plazo y oportunidad de la aludida audiencia.

Ahora bien, la jurisprudencia de Contraloría ha sido categórica al señalar que el trámite de audiencia previa debe realizarse en los procedimientos invalidatorios. En efecto, el ente de control ha expresado que "es necesario anotar que el artículo 53 de Ley $N^{\circ} 19.880$, de bases de los procedimientos administrativos que rigen los actos de la Administración, previene que 'la autoridad administrativa podrá, de oficio o a petición de parte, invalidar los actos contrarios a derecho, previa audiencia del interesado, siempre que lo haga dentro de los dos años contados desde la notificación o publicación del acto", "39.

No obstante lo anterior, y en relación a la impugnabilidad de los reglamentos dictados por el Presidente de la República, el ente de control ha señalado que el trámite de audiencia previa no procedería respecto de dichos actos. En tal sentido se ha dispuesto que "Establecido que los reglamentos que dicta el Presidente de la República revisten el carácter de actos administrativos, a los que resulta aplicable, por ende, el principio de impugnabilidad, y en lo que se refiere a la posibilidad de requerir la invalidación de tales declaraciones de voluntad, cabe señalar que no obsta a tal conclusión la circunstancia que el artículo 53 de la Ley $N^{\circ} 19.880$ establezca que la autoridad administrativa podrá invalidar los actos contrarios a derecho "previa audiencia del interesado", puesto que dicho precepto se limita a regular el procedimiento invalidatorio en un aspecto que, por su naturaleza, no es aplicable a los actos administrativos que contengan normas de general aplicación, sin que de ello se pueda deducir que tales actos no pueden ser impugnados, ante la misma autoridad que los dictó, por ser contrarios a derecho" ${ }^{40}$. 
Se abre la interrogante en relación a si lo dispuesto por la Contraloría General de la República se enmarca dentro de lo previsto en nuestro ordenamiento jurídico. En efecto, la interpretación de la Contraloría -en nuestra opinión- yerra en eximir de un trámite esencial del procedimiento de invalidación a la impugnación de los reglamentos dictados por el Presidente de la República.

Lo anterior podría generar el contrasentido de hacer susceptible de invalidación al acto que invalida, o desecha la posibilidad de hacerlo, puesto que dicho procedimiento adolecería de un vicio que puede ser caracterizado como esen$\operatorname{cial}^{41}$.

Ahora bien, en referencia al problema que se trata en este apartado, se concluye además que no sería posible eximir del trámite de audiencia previa en los casos en que la propia Contraloría ordena la invalidación de un acto administrativo, puesto que aquel trámite está establecido en la ley para resguardar la contradictoriedad de los procedimientos administrativos.

De eximirse en los antedichos casos el trámite de audiencia previa, se vulnera abiertamente lo dispuesto en el inciso $2^{\circ}$ del artículo 10 de la Ley 19.880, el cual dispone que "Los interesados podrán, en todo momento, alegar defectos de tramitación, especialmente los que supongan paralización, infracción de los plazos señalados o la omisión de trámites que pueden ser subsanados antes de la resolución definitiva del asunto. Dichas alegaciones podrán dar lugar, si hubiere razones para ello, a la exigencia de la correspondiente responsabilidad disciplinaria" ${ }^{42}$, transgrediendo asimismo, el espíritu mismo de la ley en referencia, ya que se deja en la indefensión a quien pudiese verse afectado por la dictación del acto invalidatorio.

\section{B. Invalidación de Reglamentos y Decretos Supremos}

El inciso $3^{\circ}$ del artículo $3^{\circ}$ de la Ley de Procedimiento Administrativo señala que "Los actos administrativos tomarán la forma de decretos supremos y resoluciones" ${ }^{43}$. En lo particular, "El decreto supremo es la orden escrita que dicta el Presidente de la República o un Ministro 'Por orden del Presidente de la República', sobre asuntos propios de su Competencia" ${ }^{44}$.

Al coordinar la norma transcrita con lo dispuesto en el artículo 53 de la citada ley, se puede concluir que los decretos supremos están afectos a la invalidación. Esta conclusión alcanza también a los reglamentos, puesto que estos

41 Véase Bermúdez Soto (2010), p. 102.

42 Ley $\mathrm{N}^{\circ} 19.880$, de 2003.

43 Ley $\mathrm{N}^{\circ} 19.880$, de 2003.

44 Artículo $^{\circ}$ inciso $4^{\circ}$ de la Ley $N^{\circ} 19.880$, de 2003. 
formalmente están contenidos en decretos supremos dictados por la Primera Magistratura, los cuales "necesariamente deben ser suscritos por el Presidente de la República y además, por el Ministro respectivo"45.

La tesis expuesta se ve reforzada por el principio de impugnabilidad dispuesto en el inciso $1^{\circ}$ del artículo 15 de la referida Ley 19.880. Dicha disposición señala que "Todo acto administrativo es impugnable por el interesado mediante los recursos administrativos de reposición y jerárquico, regulados en esta ley, sin perjuicio del recurso extraordinario de revisión y de los demás recursos que establezcan las leyes especiales", constituyéndose en la regla general.

Asimismo, el inciso segundo del citado artículo, que establece la excepción a la regla general, señalando que "los actos de mero trámite son impugnables sólo cuando determinen la imposibilidad de continuar un procedimiento o produzcan indefensión" ${ }^{46}$, no excluye del principio general de impugnabilidad a los decretos supremos y a los reglamentos, siendo, en consecuencia, susceptibles de declaración de invalidación por parte de la autoridad que los dictó.

Sin perjuicio de lo dicho, han existido voces que han señalado que la invalidación no se aplica a los reglamentos. En efecto, "el reglamento cambia el ordenamiento jurídico, pues modifica o deroga normas vigentes, o introduce a él otras. No sucede lo mismo con el acto administrativo, que es una manifestación de voluntad de ejecución de normas. Enseguida, se distinguen en que, por regla general, los actos administrativos son singulares, en cambio, los reglamentos son generales" ${ }^{\prime 4}$.

La doctrina recién referida fue adoptada por la Contraloría General de la República el año 2003, luego de entrada en vigencia la Ley 19.880, al señalar que "es necesario manifestar que el uso de la atribución del Servicio de Impuestos Internos, de fijar normas e impartir instrucciones, se materializa en un acto que no se enmarca en ninguno de los conceptos de acto administrativo que contiene el artículo $3^{\circ}$ de Ley $N^{\circ} 19.880$, toda vez que se trata de una potestad normativa, reguladora, cuyo ejercicio corresponde que sea ponderado exclusivamente por el Servicio" $" 48$.

Con lo anterior, queda claro que aquellos actos de carácter normativo quedan excluidos de la aplicación de la Ley 19.880, con lo cual, en consecuencia, no cabría invalidación respecto de aquellos.

\footnotetext{
45 Tribunal Constitucional, 25 de Enero de 1993, "Requerimiento respecto del Decreto Supremo $N^{\circ}$ 66, del Ministerio de Vivienda y Urbanismo, de 19 de junio de 1992, que Aprueba el Plan Regulador Intercomunal La Serena - Coquimbo", Rol No 153 (Requerimiento de inconstitucionalidad).

46 Artículo 15 inciso $2^{\circ}$ de la Ley $N^{\circ} 19.880$, de 2003.

47 Rojas, Andrea y Jiménez, Guillermo. Doctrina Constitucional del Presidente Ricardo Lagos Escobar (2000-2006). Tomo II. Ministerio Secretaría General de la Presidencia, Santiago, 2008, p. 337.

48 Dictamen $\mathrm{N}^{\circ} 39.353$, de 2003
} 
Sin embargo, una interpretación posterior de la propia Contraloría ha señalado la procedencia de la invalidación respecto de aquel tipo de actos. En efecto, "en lo que se refiere a la noción de acto administrativo, cabe señalar que el articulo $3^{\circ}$ de la ley $N^{\circ} 19.880$, sobre Bases de los Procedimientos Administrativos que Rigen los Actos de los órganos de la Administración del Estado, establece que "las decisiones escritas que adopte la Administración se expresarán por medio de actos administrativos", esto es, a través de "decisiones formales que emitan los órganos de la Administración del Estado en las cuales se contienen declaraciones de voluntad, realizadas en el ejercicio de una potestad pública", los cuales "tomarán la forma de decretos supremos y resoluciones", noción que, en los términos amplios en que se formula, permite incluir en ella tanto las decisiones de alcance general, como las de contenido o efectos singulares.

El mismo artículo $3^{\circ}$ dispone, en su inciso final, que "los actos administrativos gozan de presunción de legalidad, de imperio y exigibilidad frente a sus destinatarios, desde su entrada en vigencia, "salvo que mediare una orden de suspensión dispuesta por la autoridad administrativa dentro del procedimiento impugnatorio o por el juez, conociendo por la vía jurisdiccional, precepto que, en relación al principio de impugnabilidad de los actos administrativos y a la suspensión de sus efectos, no formula distinción alguna en cuanto al contenido o alcance de las declaraciones de voluntad que se contengan en dichos actos".

En el mismo sentido, el inciso segundo del artículo 51 de la Ley 19.880, respecto de los efectos jurídicos de los actos administrativos, expresados en decretos o resoluciones, determina que aquellos se producirán desde su notificación o publicación, "según sean de contenido individual o general".

Ratifica el señalado carácter de los reglamentos lo establecido en el artículo 48, letra a), de la antedicha Ley 19.880, el cual ordena la publicación en el Diario Oficial de aquellos actos administrativos que "contengan normas de general aplicación o que miren al interés general", como ocurre en el caso de los reglamentos dictados en ejercicio de la potestad reglamentaria del Presidente de la República.

Enseguida, cabe agregar que conforme lo establece el inciso segundo del artículo $3^{\circ}$ de la Ley 18.575, Orgánica Constitucional de Bases Generales de la Administración del Estado, cuyo texto refundido, coordinado y sistematizado fue fijado por el decreto con fuerza de ley $\mathrm{N}^{\circ} 1 / 19.653$, de 2000, del Ministerio Secretaría General de la Presidencia de la República, la Administración del Estado deberá observar, entre otros, el principio de impugnabilidad de los actos administrativos, imponiéndole, por ende, tanto la prerrogativa como el deber de revisar la juridicidad de sus decisiones, en tanto que su artículo 10 dispone que "los actos administrativos serán impugnables mediante los recursos que establezca la ley, siendo pertinente añadir que entre las finalidades de tal im- 
pugnación se encuentra, desde luego, la de dejar sin efecto los actos emitidos, por ser contrarios a derecho".

Establecido que los reglamentos que dicta el Presidente de la República revisten el carácter de actos administrativos, a los que resulta aplicable, por ende, el principio de impugnabilidad, y en lo que se refiere a la posibilidad de requerir la invalidación de tales declaraciones de voluntad, cabe señalar que no obsta a tal conclusión la circunstancia que el artículo 53 de la Ley 19.880 establezca que la autoridad administrativa podrá invalidar los actos contrarios a derecho "previa audiencia del interesado", "puesto que dicho precepto se limita a regular el procedimiento invalidatorio en un aspecto que, por su naturaleza, no es aplicable a los actos administrativos que contengan normas de general aplicación, sin que de ello se pueda deducir que tales actos no pueden ser impugnados, ante la misma autoridad que los dictó, por ser contrarios a derecho"49.

Por último, cabe señalar que en relación al Dictamen $\mathrm{N}^{\circ} 39.353$, de 2003, anteriormente citado, la propia Contraloría precisa que "corresponde aclarar que tales pronunciamientos recayeron en sendas presentaciones referidas a la potestad de ciertos órganos públicos para impartir instrucciones, las cuales, en la medida que no constituyan una decisión formal de la Administración, ni importen una declaración de juicio, constancia o conocimiento de alguno de sus órganos, efectivamente, no se enmarcan en ninguno de los conceptos de acto administrativo que describe el artículo $3^{\circ}$ de la Ley $N^{\circ} 19.880^{\prime \prime 50}$.

\section{Invalidación de Actos Administrativos cuya generación Se produce a TRAVÉS DE PROCEDIMIENTOS REGLADOS}

Lo dispuesto en el párrafo anterior es uno de los problemas de la invalidación que está intrínsecamente relacionado con lo que se expondrá a continuación. En efecto, en este apartado se quiere dilucidar qué sucede en aquellos casos en que se somete a invalidación un acto administrativo cuyo procedimiento se encuentra reglado pormenorizadamente en la ley habilitante.

En efecto, a través del dictamen $N^{\circ}$ 52.241, de 2002, la Contraloría General señaló, en síntesis, que "siendo el Sistema de Evaluación de Impacto Ambiental un procedimiento reglado, las resoluciones de calificación ambiental sólo pueden modificarse, además de las situaciones en que ello procede conforme con la propia regulación del procedimiento, en caso de invalidación o previa evaluación del impacto ambiental de las modificaciones de un proyecto sometido al Sistema" ${ }^{51}$.

\footnotetext{
49 Dictamen $\mathrm{N}^{\circ} 39.979$, de 2010.

50 Dictamen $\mathrm{N}^{\circ} 39.979$, de 2010.

51 Dictamen $\mathrm{N}^{\circ}$ 34.021, de 2003.
} 
Como se desprende de esta interpretación, la invalidación concurre simultáneamente con las causales de extinción que el procedimiento reglado establece para el acto en cuestión, debido que, al tenor de lo dispuesto en el artículo 53 , la invalidación es una causal de extinción anormal o provocada del acto administrativo $^{52}$, la cual se produce porque aquel acto adolece de un vicio que lo hace ser contrario a Derecho. El vicio en cuestión puede ser cualquier vicio del acto administrativo, como la incompetencia, la desviación de fin, la falta de motivo, el error de motivo, etc. ${ }^{53}$.

Por lo demás, el objetivo que pretende alcanzar el órgano de control con la jurisprudencia en cuestión es que los actos administrativos que se producen como consecuencia de un procedimiento reglado no sean modificados o dejados sin efecto discrecionalmente, lo cual "ha sido confirmado en materias tan diversas y especiales como la aplicación de medidas disciplinarias (Dictámenes $\mathrm{N}^{\circ} \mathrm{s}$. 70.493 de $1969,57.317$ de $1971,12.488$ y 26.568, ambos de 1972, 23.592 de 1979, 21.954 de 1983, 30.528 de 1984, 22.943 de 1987, 27.396 de 1988, y 199 de 1994, entre otros); el proceso calificatorio (Dictámenes $\mathrm{N}^{\circ} \mathrm{s} 20.360$ de 1999 y 8.977 de 2002); las concesiones de radiodifusión televisivas (Dictamen $\mathrm{N}^{\circ}$ 41.962 de 2001); la determinación del capital propio (Dictamen $\mathrm{N}^{\circ} 17.001 \mathrm{de}$ 1992); la fijación de estructura, nivel y mecanismos de indexación de las tarifas de los servicios suministrados por empresas de telefonía local que no gozan de libertad de precios (Dictamen $\mathrm{N}^{\circ} 46.234$ de 2001), y, también, respecto del sistema de evaluación de impacto ambiental (Dictamen $\mathrm{N}^{\circ} 44.032$ de 2002, anteriormente citado)" ${ }^{54}$, objetivo que se cumple cabalmente en el proceso invalidatorio, ya que en aquel se establecen trámites mínimos que permiten el control de la discrecionalidad de la decisión de la autoridad competente.

\section{Plazo para invalidar: ¿PRescripción o Caducidad?}

Dentro del estudio y el ejercicio de la invalidación por parte de los órganos de la Administración del Estado, tal vez una de las materias más controvertidas dice relación con la oportunidad de la misma, y más precisamente con respecto al plazo para el ejercicio de la potestad invalidatoria. En efecto, de la revisión del artículo 53 de la Ley 19.880 fluye de inmediato que ella confiere al órgano administrativo correspondiente un plazo de 2 años para retirar del ordenamiento aquellos actos que lo contravienen, debiendo entenderse que dicho plazo comienza a computarse desde el momento en que dicho acto produce sus efectos, esto es, desde su notificación (actos de efecto singular) o bien desde su publicación (actos de efecto general) ${ }^{55}$.

52 Cfr. Rojas y Jiménez (2008), p. 326

53 Cfr. Rojas y JimÉnez (2008), p. 326.

54 Dictamen $\mathrm{N}^{\circ}$ 20.433, de 2003.

55 Conforme a los términos del artículo 51 de la Ley $N^{\circ} 19.880$, de 2003 
En tal sentido, cuando la autoridad de suyo decide retirar (invalidar) un acto contrario a Derecho, cuenta con un plazo de 2 años desde la entrada al ordenamiento del acto para ejercer dicha atribución. Sin embargo, el problema surge cuando la invalidación es requerida a petición de parte, y más precisamente respecto de los efectos de la presentación de la respectiva solicitud, lo que nos lleva a preguntarnos si el actuar del interesado goza del mérito para interrumpir y/o suspender el plazo para ejercer la potestad, o, lo que es lo mismo, sostener si el plazo de los 2 años es un plazo de caducidad o prescripción.

Los efectos de esta distinción no son menores, puesto que predicar que estamos en presencia de un plazo de prescripción importaría sostener la procedencia de su suspensión y/o interrupción con motivo de la solicitud de invalidación, por lo que bastaría solamente con que el particular requiera la invalidación dentro de los 2 años, para que la Administración pudiere declararla en cualquier momento, incluso transcurridos largamente los dos años previstos en el artículo 53 de la Ley 19.880.

A contrario sensu, sostener que estamos frente a un plazo de caducidad, que como tal atiende únicamente al hecho objetivo del transcurso del plazo, importaría la improcedencia tanto de la interrupción como de la suspensión (instituciones propias de la prescripción), por lo que transcurridos los 2 años expiraría irredargüiblemente el plazo para invalidar.

Al respecto, la jurisprudencia administrativa ha sostenido que "la disposición precitada [artículo 53 de la Ley 19.880] contempla la obligación de la autoridad administrativa para dejar sin efecto los actos que ha emitido con infracción a derecho, sujeto a las restricciones que para tal efecto ha previsto el propio ordenamiento jurídico y la jurisprudencia administrativa, entre las cuales cabe destacar que esa atribución debe ejercerse dentro del término de dos años contados desde la notificación o publicación del acto viciado. En efecto, tal como lo ha sostenido la jurisprudencia administrativa contenida, entre otros, en el dictamen $N^{\circ} 52.014$, de 1970, ha manifestado que los plazos fatales, como ocurre en aquellos prefijados para el ejercicio de la actuación en estudio [invalidación], son de caducidad y no de prescripción, por lo cual no pueden interrumpirse ni suspenderse por virtud de la interposición del recurso dentro de su término, porque en la caducidad se atiende solamente al hecho objetivo del transcurso del plazo. De esta manera, entonces, en armonía con lo informado por esta Contraloría General en su dictamen $N^{\circ} 8.665$, del año en curso, aparece de manifiesto que el referido plazo es de caducidad y no de prescripción, como erradamente afirma el recurrente, razón por la cual no admite interrupción de ninguna especie, y por ende, la solicitud realizada por su representada, no pudo tener ese mérito" ${ }^{56}$.

56 Dictamen $\mathrm{N}^{\circ}$ 18.353, de 2009. 
Concordamos con la posición de la Contraloría General de la República en orden de que nos encontramos frente a un plazo de caducidad y no de prescripción, toda vez que estamos frente a una potestad cuyos contornos y límites han sido delineados cuidadosamente por el legislador, circunscribiéndolos en el orden temporal restrictivamente a un plazo de 2 años.

No obstante lo anterior, no podemos sino hacer presente el inconveniente resultante, tratándose de las solicitudes de invalidación presentadas por las personas respecto de las cuales la inacción de la Administración (dentro del plazo de los 2 años), privaría al particular de la posibilidad de retirar el acto del ordenamiento, contraviniendo el principio del nemo auditur propiam turpitudinem allegans. Sin embargo, estimamos que ello no es óbice para perseguir la responsabilidad administrativa del funcionario (por la dilación en la sustanciación del procedimiento invalidatorio) y reclamar en definitiva la ineficacia del acto en sede jurisdiccional.

De esta manera, al ser la invalidación una potestad (poder jurídico finalizado) conferida por el legislador (Ley 19.880) a la autoridad administrativa, debe circunscribirse a la esfera de competencia temporal expresamente prevista al efecto $(2 \text { años })^{57}$, por lo que, en estricto rigor, la autoridad administrativa estaría desprovista de la atribución para ejercerla transcurrido dicho plazo, lo que ha sido refrendado por la jurisprudencia de la Contraloría General ${ }^{58}$. Sin embargo, llama la atención que la propia Contraloría disponga excepciones a dicha regla (de competencia) al admitir el ejercicio de la potestad invalidatoria transcurrido incluso dicho plazo, cuando su ejercicio reconozca como antecedente el cumplimiento de una orden (dictamen) impartida por la referida entidad de control $^{59}$, más aún si la propia jurisprudencia administrativa ha señalado expresamente que la regla limitativa del plazo previsto debe ser interpretada en forma restrictiva ${ }^{60}$.

57 En ese sentido, véanse los artículos 6 y 7 de la Constitución Política de la República.

58 En este sentido, la jurisprudencia de Contraloría - mediante Dictamen No 19.937, de 2010- ha sostenido que "Sobre el particular, la jurisprudencia administrativa contenida en los dictámenes $N^{\circ}$ s. 19.682, de 2007 y 9.820, de 2009, ha señalado que no procede la invalidación de una patente de alcoholes, en el caso que desde su otorgamiento, aunque erróneo, haya transcurrido el plazo de dos años para invalidar un acto contrario a derecho, según lo dispuesto en el artículo 53 de la Ley $N^{\circ} 19.880$ ".

59 En efecto, por medio de Dictamen N 62.378, de 2009, Contraloría General ha sostenido que "Ahora bien, en lo concerniente a la aplicación, en el asunto de la especie, del plazo de dos años establecido en el artículo 53 de la ley $N^{\circ} 19.880$, es menester señalar que este Organismo de Control ha informado en sus dictámenes $N^{\circ}$ s. 56.391, de 2008, y 35.906, de 2009, entre otros, que la obligatoriedad de sus pronunciamientos es pura y simple, sin que proceda someterla a plazo o condición alguna. De este modo, no cabe sostener que los dictámenes $N^{\circ}$ s. 23.114, de 2007, y 4.168, de 2008, hayan quedado sin efecto por haber transcurrido el referido término de dos años, ya que ello importaría, en los hechos, dejar entregada su eficacia a la diligencia de la Administración para disponer la invalidación del acto administrativo viciado. En otro orden de ideas, se debe anotar que, tal como se expresó en los referidos dictámenes $N^{\circ}$ s. 56.391, de 2008, y 35.906, de 2009, la sujeción a los pronunciamientos de esta Contraloría General resulta obligatoria para la Administración tanto para el caso concreto a que se refirieron como también en todas aquellas situaciones que se encuadren dentro del contexto del dictamen, extendiéndose el efecto de los mismos a todos los casos análogos a los que resuelven. En este sentido, no ha procedido que la autoridad dé un tratamiento diverso al recurrente, quien se encontraba en la misma situación jurídica de aquéllos que obtuvieron un pronunciamiento favorable mediante la emisión de los dictámenes $N^{\circ}$ s. 23.114 , de 2007, y 4.168, de 2008. Por lo anterior, la decisión del Ministerio de Defensa Nacional, a través de la Subsecretaría de Investigaciones, en orden a no acceder a la solicitud de invalidación formulada por el señor Mc Lean por haber transcurrido el plazo de dos años contemplado en el artículo 53 de la ley $N^{\circ} 19.880$, no se ha ajustado a derecho".

60 En tal sentido, la jurisprudencia de Contraloría es clara al señalar que "Es necesario tener en cuenta que la regla limitativa del artículo 53 antes referida debe ser interpretada en forma estricta, toda vez que involucra la permanencia o perseverancia de situaciones irregulares, 


\section{E. No EXISTE PRECLUSIÓN EN EL EJERCicio DE LA POTESTAD INVALIDATORIA}

Como ya se ha señalado, la invalidación es una potestad. Lo anterior produce consecuencia en el plano del procedimiento invalidatorio, ya que ello permite afirmar que no existiría preclusión ni cosa juzgada administrativa que impida a la administración invalidar un acto sobre el cual se hicieron valer otros medios de impugnación.

Por lo demás, es preciso reiterar que al establecer el artículo 15 de la Ley 19.880 que la regla general es que todo acto administrativo es impugnable por el interesado mediante los recursos administrativos de reposición y jerárquico, sin perjuicio del recurso extraordinario de revisión y de los demás recursos que establezcan las leyes especiales, nada obsta a que una vez ejercitados aquellos remedios procedimentales, pueda ejercerse la invalidación.

Así, y refiriéndose derechamente a la invalidación, es posible advertir que esta siempre procederá, sin perjuicio de que la ley dispone que el límite para ejercitar dicha potestad es que esta se ejercite dentro de dos años contados desde que el acto administrativo impugnado produce sus efectos, en conformidad con lo establecido en el citado artículo 53 de la Ley 19.880.

Cabe agregar, que si el acto impugnado es un acto trámite, tal acto no produciría derechos para quienes son sus destinatarios, pudiendo retrotraerse, mediante la invalidación, dicho procedimiento hasta el estadio procesal administrativo anterior, lo cual refuerza la tesis sostenida.

\section{F. ¿Invalidación o Nulidad de Derecho Público? Frente a la entidad DEL VICIO}

Como hemos señalado, existe una identidad sustancial entre la Invalidación y la Nulidad, toda vez que ambas se constituyen en el efecto jurídico de un actuar ilegal (Invalidación) y, en definitiva, de un actuar en contravención a la Constitución y a las normas dictadas conforme a ella (Nulidad). Sin perjuicio de concurrir una diferencia adjetiva desde el punto de vista de la sede y el procedimiento para requerir su declaración y/o su constatación.

En efecto, la Invalidación supone la potestad de la Administración para dejar sin efecto aquellos actos "contrarios a derecho", a través de un procedimiento administrativo previsto en el artículo 53 de la Ley 19.880 y que en lo sustancial demanda la apertura de una audiencia previa del interesado y que en caso de

lo que debe armonizarse con el principio constitucional de juridicidad que obliga a todos los entes, órganos y servicios del Estado a someterse al ordenamiento jurídico, según lo prescriben los artículos $6^{\circ}$ y $7^{\circ}$ de la Carta Suprema" (Dictamen $N^{\circ}$ 56.021, de 2004). 
finalizar con un acto invalidatorio (sea parcial o total), se concede acción para recurrir ante los tribunales ordinarios en procedimiento breve y sumario.

Por su parte, la Nulidad de Derecho Público, importa el preciso efecto jurídico que la Constitución ha previsto para aquellos actos que la contravienen (investidura/competencia y procedimiento) conforme a los términos del artículo 7 de la Constitución ${ }^{61}$, y que como tal importa un acto jurisdiccional que declare y/o constate su concurrencia.

Pues bien, podrán advertirse semejanzas y diferencias entre la invalidación y la nulidad, las que a su vez se entremezclan tratándose del antecedente mismo de ambas, esto es, la contravención a Derecho, toda vez que la Invalidación importa una causal genérica de contravención a Derecho dispuesta en el contexto de la regulación prevista en la Ley 19.880, sobre Procedimiento Administrativo. Es precisamente dicha norma la que viene a "flexibilizar" - con la consagración del principio de no formalización- la procedencia de la invalidación desde el momento que precisa que no todo vicio afecta la validez del procedimiento, exigiendo para que ello ocurra que el vicio tenga la entidad de recaer en un requisito esencial (sea por su naturaleza o por mandato del ordenamiento) y a la vez irrogue un perjuicio. En consecuencia, para que un vicio afecte la validez de un procedimiento (acto administrativo), este debe tener una entidad determinada (esencialidad) y originar un "perjuicio" (daño) a los particulares.

De esta forma, pareciera que la regla amplia original de "contrariedad a Derecho" como presupuesto de la Invalidación se "limita” por la propia Ley 19.880, al disponer que no todo vicio afecta la validez (conformidad a Derecho) del acto administrativo, sino que lo hace solo en la medida que sea esencial y cause un perjuicio.

Surge una primera interrogante en orden a determinar cuándo el vicio es esencial a fin de exponer el acto viciado a una invalidación. En primer término, debemos señalar que va a ser esencial cuando expresamente así lo prevea el ordenamiento jurídico (legislador), cuyos casos son más bien escasos ${ }^{62}$, por lo que corresponderá determinar la segunda circunstancia, es decir, cuando recaiga en un requisito esencial por la naturaleza del mismo, calificación entregada

\footnotetext{
61 Véase Soto KLoss (1996).

$62 \mathrm{Al}$ disponer el artículo $9^{\circ}$ bis de la Ley $\mathrm{N}^{\circ}$ 19.300, Ley de Bases Generales del Medio Ambiente, 9 de marzo de 1994 (introducido por la Ley $\mathrm{N}^{\circ}$ 20.417, que crea el Ministerio, el Servicio de Evaluación Ambiental y la Superintendencia del Medio Ambiente, 26 de enero de 2010) que 'La Comisión a la cual se refiere el artículo 86 o el Director Ejecutivo, en su caso, deberán aprobar o rechazar un proyecto o actividad sometido al Sistema de Evaluación de Impacto Ambiental sólo en virtud del Informe Consolidado de Evaluación en lo que dice relación con los aspectos normados en la legislación ambiental vigente. En todo caso, dicho informe deberá contener, los pronunciamientos ambientales fundados de los organismos con competencia que participaron en la evaluación, la evaluación técnica de las observaciones planteadas por la comunidad y los interesados, cuando corresponda, así como la recomendación de aprobación o rechazo del proyecto". Añadiendo el inciso $2^{\circ}$ que "El incumplimiento a lo señalado en el inciso anterior se considerará vicio esencial del procedimiento de calificación ambiental".
} 
a la autoridad administrativa, por lo que dota a esta autoridad de un espacio de ponderación (discrecionalidad), ponderación a nuestro juicio riesgosa.

Por lo anterior, estimamos que el ejercicio de la potestad invalidatoria debe necesariamente considerar el principio de no formalización, restringiendo el ámbito de la invalidación. De esta manera, surge la interrogante en orden a si la necesariedad de la concurrencia de un vicio esencial (sea por la naturaleza del mismo o por mandato del ordenamiento) trastoca el vicio de procedimiento en cuanto uno de los presupuestos de la acción de nulidad de derecho público.

\section{Conclusiones}

La Ley 19.880 viene a consagrar la potestad invalidatoria de los órganos de la administración del Estado, que como tal importa un poder-deber que -ante una infracción a Derecho- fuerza a la autoridad administrativa a instar el correspondiente procedimiento invalidatorio.

Si bien la Ley 19.880 vino a despejar uno de los aspectos más debatidos en la doctrina respecto de legalidad del ejercicio de la referida potestad invalidatoria por parte de la Administración del Estado, irrumpió con dudas respecto de la aplicación y operatividad del procedimiento invalidatorio, en materias tales como la necesariedad de la audiencia previa, la esencialidad del vicio, los actos susceptibles de ser invalidados, el plazo de la invalidación frente a solicitudes a petición de parte, etc.

Varias de las interrogantes planteadas en esta investigación han sido generosamente resueltas por la jurisprudencia administrativa emanada de Contraloría General, por ejemplo, al precisar la autoridad llamada a invalidar el acto, al consagrar que estamos en presencia de un plazo de caducidad y no de prescripción, etc.

Sin embargo, aún persisten materias que no han podido ser suficientemente abordadas por la jurisprudencia administrativa, ni la doctrina, aún escasa en nuestro medio, que hacen vislumbrar la posibilidad de instar un remedio legislativo que permita hacer coexistir el ejercicio de dicha potestad con un estricto y pleno respeto de los derechos de los ciudadanos.

Finalmente, resta señalar que una correcta aplicación de la invalidación administrativa posibilita un mayor resguardo de los derechos de las personas. En sentido contrario, una aplicación antojadiza y discrecional puede generar mayores problemas de los que, eventualmente, podría resolver. Así, la única aplicación posible que se vislumbra para esta institución, es que ella sea ejercida 
dentro del contexto de las potestades del órgano que la aplica, encaminándola al bien común, con pleno respeto y sujeción a la Constitución y a los derechos por ella garantizados. 


\section{BibLIOGRAFÍA}

Aylwin Azócar, Patricio. Derecho Administrativo. Santiago: Editorial Universidad Nacional Andrés Bello, 2006.

Bermúdez Soto, Jorge. Derecho Administrativo General. Santiago: Ediciones LegalPublishing, 2010.

Bermúdez Soto, Jorge. "El principio de confianza legítima en la actuación de la Administración como límite a la potestad invalidatoria". Revista de Derecho (Valdivia), Volumen XVIII, No 2. Facultad de Derecho de la Universidad Austral, Valdivia, 2005.

Bocksang Hola, Gabriel. El Procedimiento Administrativo Chileno. Estudio Analítico y Sistemático de Coherencia. Santiago: Editorial LexisNexis, 2006.

Boloña Kelly, Germán. El Acto Administrativo. $2^{\text {a }}$ Edición. Santiago: Ediciones LegalPublishing, 2007.

Celis Danzinger, Gabriel. Curso de Derecho Administrativo. Tomo I. Santiago: Ediciones PuntoLex, 2010.

Cortés Sepúlveda, Aristóteles. “¿Texto, contexto o pretexto? Por una teoría normativa de la seguridad jurídica". Actas de las XXXIV Jornadas de Derecho Público. Facultad de Derecho de la Pontificia Universidad Católica de Chile, Santiago: Lexis Nexis, 2005.

Ducci Claro, Carlos. Derecho Civil. Parte General. Santiago: Editorial Jurídica de Chile, 2005.

Nogueira AlcalÁ, Humberto. "El principio de proporcionalidad y su aplicación en Sudamérica por la jurisdicción constitucional, con especial mención al Tribunal Constitucional chileno". En: CArbonell, Miguel (Edit.). El principio proporcional en la interpretación jurídica. Santiago: Librotecnia, 2010.

Olguín JuÁrez, Hernán. Extinción de los actos administrativos. Revocación, invalidación y decaimiento. Santiago: Editorial Jurídica de Chile, 1961.

Poblete Vinaixa, Julia. Actos y Contratos Administrativos. $5^{\text {a }}$ Edición. Santiago: Editorial LegalPublishing, 2010.

Rojas, Andrea y JimÉnez, Guillermo. Doctrina Constitucional del Presidente Ricardo Lagos Escobar (2000-2006). Tomo II. Ministerio Secretaría General de la Presidencia, Santiago, 2008.

Sото KLoss, Eduardo. Derecho Administrativo. Temas Fundamentales. Santiago: Editorial LegalPublishing, 2009.

Soто KLoss, Eduardo. “La Ley 19.880, sobre Procedimientos administrativos, ¿"Aleluya" o "Miserere"?". En: Soto Kloss, Eduardo (Edit.). Ley $N^{\circ}$ 19.880, sobre Procedimientos Administrativos. Santiago: Ediciones Universidad Santo Tomás, 2003.

Soto Kloss, Eduardo. Derecho Administrativo. Bases Fundamentales. Santiago: Editorial Jurídica de Chile, 1996.

VARGAS ZINCKe, Osvaldo. "Algunos aspectos de la invalidación en la juris- 
prudencia de la Contraloría General de la República". En: Verdugo Marinkovic, Mario (Dir.). Gaceta Jurídica, № 178. Santiago: Editorial Jurídica ConoSur Limitada, 1995.

\section{NORMAS}

Constitución Política de la República.

Ley $N^{\circ} 19.880$, Ley de Bases de los procedimientos administrativos que rigen los actos de los Órganos de la Administración del Estado, Diario Oficial, 22 de mayo de 2003.

Ley N $\mathrm{N}^{\circ}$ 19.300, Ley de Bases Generales del Medio Ambiente, Diario Oficial,9 de marzo de 1994.

\section{JURISPRUDENCIA}

Requerimiento respecto del Decreto Supremo No 66, del Ministerio de Vivienda y Urbanismo, de 19 de junio de 1992, que Aprueba el Plan Regulador Intercomunal La Serena - Coquimbo, Rol No 153 (Requerimiento de inconstitucionalidad), Tribunal Constitucional, 25 de enero de 1993.

Dictamen N²4.192, de 1960, de la Contraloría General de la República. Dictamen N $N^{\circ} 4.049$, de 1969, de la Contraloría General de la República. Dictamen $N^{\circ} 21.719$, de 1972, de la Contraloría General de la República. Dictamen $N^{\circ} 11.177$, de 1988, de la Contraloría General de la República. Dictamen $N^{\circ} 28.514$, de 1992, de la Contraloría General de la República. Dictamen N 10.667, de 1994, de la Contraloría General de la República. Dictamen $N^{\circ} 23.851$, de 1995, de la Contraloría General de la República. Dictamen $N^{\circ} 12.500$, de 2002, de la Contraloría General de la República. Dictamen $N^{\circ} 24.337$, de 2002, de la Contraloría General de la República. Dictamen N²0.433, de 2003, de la Contraloría General de la República. Dictamen $N^{\circ} 34.021$, de 2003, de la Contraloría General de la República. Dictamen $N^{\circ} 39.353$, de 2003, de la Contraloría General de la República. Dictamen $N^{\circ} 48.554$, de 2004, de la Contraloría General de la República. Dictamen $N^{\circ} 4.933$, de 2005, de la Contraloría General de la República. Dictamen $N^{\circ} 42.176$, de 2005, de la Contraloría General de la República. Dictamen $N^{\circ}$ 7.941, de 2006, de la Contraloría General de la República. Dictamen $N^{\circ} 33.451$, de 2006, de la Contraloría General de la República. Dictamen N $N^{\circ} 38.612$, de 2006, de la Contraloría General de la República. Dictamen $N^{\circ}$ 16.238, de 2007, de la Contraloría General de la República. Dictamen $N^{\circ} 17.329$, de 2007, de la Contraloría General de la República. Dictamen $N^{\circ}$ 23.120, de 2007, de la Contraloría General de la República. Dictamen N³3.200, de 2007, de la Contraloría General de la República. Dictamen $N^{\circ}$ 7.348, de 2008, de la Contraloría General de la República. Dictamen $N^{\circ} 17.563$, de 2008, de la Contraloría General de la República. Dictamen $N^{\circ}$ 19.551, de 2008, de la Contraloría General de la República. 
Dictamen $\mathrm{N}^{\circ} 36.701$, de 2008, de la Contraloría General de la República. Dictamen N ${ }^{\circ} 8.058$, de 2009, de la Contraloría General de la República. Dictamen N ${ }^{\circ} 18.353$, de 2009, de la Contraloría General de la República. Dictamen $N^{\circ} 62.378$, de 2009, de la Contraloría General de la República. Dictamen $N^{\circ} 65.786$, de 2009, de la Contraloría General de la República. Dictamen No 19.937, de 2010, de la Contraloría General de la República. Dictamen N 22.983 de 2010, de la Contraloría General de la República. Dictamen No 39.979, de 2010, de la Contraloría General de la República. 